\title{
La Bejahung y sus destinos Locuras, sujeto y enunciación
}

\author{
The Bejahung and its destinies. \\ Madness, subject and enunciation
}

\section{Damián Coirini}

\section{RESUMEN:}

El presente texto se configura a partir de la transcripción de clases teóricas dictadas en el marco del programa anual de la cátedra "Psicología Clínica II A" de la Facultad de Psicología de la UNR, correspondientes al año lectivo 20I3. En el mismo se desarrollan problemáticas introducidas por Jacques Lacan al estudio de las estructuras freudianas de las psicosis, tomando como referencia el marco de su Seminario dictado en los años I 95 5-56. Se recorren los argumentos y los problemas que surgen del intento de aislar un mecanismo diferencial entre neurosis y psicosis: la problemática Bejahung - Austossung - Verwerfung. Esto se desarrolla desde una particular posición de lectura adoptada por Lacan: posición que se caracteriza por leer el texto -tanto el texto freudiano como la enunciación psicótica- como una lengua extranjera. Por último, se presentan y explicitan los fundamentos teóricos de la estructura del programa de la materia antes mencionada.

Palabras Clave:

Psicosis - Bejahung - Verwerfung Simbólico - Denegación

\section{SUMMARY:}

The given text is made from the theoretic classes transcriptions. Those had taken place along the year 2013, within the framework of the subject "Psicología Clínica II A" from the "Facultad de Psicología" at "Universidad Nacional de Rosario". While retaking the Jacques Lacan seminaries from the years I955 and I956, this text introduces the issues presented by Lacan itself reading the freud's psychoses structures. Is on the attempt to isolate the mechanism that sets apart the neurosis from the psychosis: the topic Bejahung - Austossung Verwerfung that these classes took place. The topic is developed from a particular position adopted by Lacan: position in which he reads the text -both freud's text and the psychotic speech-as if they are foreign languages. At last the theoretical fundaments of the previously mentioned subjects program are presented and explained.

KEY WORDS:

Psychoses - Bejahung - Verwerfung -

Symbolic - Negation 

Hoy vamos a comenzar con el primer punto de la Unidad temática 1 del programa general de la materia. Esa unidad se llama "Locuras"1; Locuras, en plural, ya que vamos a ver que tiene una consideración explícita en Lacan entre la primera y segunda sesión del Seminario 3, llamado originalmente por él: "Las estructuras freudianas de las psicosis” (LACAN, I955I956), justamente para no homologar locuras a psicosis, también planteadas en plural, lo que sitúa de entrada un campo con ciertas dispersiones que dan cuenta de una heterogeneidad insistente, tanto en el campo de la clínica psiquiátrica como en el de la práctica del psicoanálisis.

El primer punto de esta unidad tiene como contenido la Bejahung, lo que se traduce comúnmente como afirmación. En sentido freudiano, incluso tal como es leído por Lacan, se traduce generalmente como afirmación primordial.

"La Bejabung y sus destinos" dice el programa, podríamos leer la Bejabung y sus retornos, o sus consecuencias. $\mathrm{La}$ Bejahung es un término alemán y aquí ya empezamos con la problemática de la traducción de estos términos. Este programa los confronta con una economía del lenguaje y de la lengua que es imposible reducir a una lengua común. En este punto, en el Seminario 3, Lacan plantea que la posición de Freud frente a la lectura de las memorias de Schreber es la posición, justamente, de aquel que lee una lengua extranjera. ¿Pero cómo? Si las memorias están escritas en lengua alemana, que era la lengua materna de Freud. De acuerdo, el psicótico en algún punto crea su propia lengua: el famoso lenguaje fundamental (Grundsprache) de Schreber. Pero a la vez Lacan plantea que la operación fundamental de Freud con respecto a ese texto es justamente leerlo como una lengua extranjera (LACAN, I955-I956). ¿Qué consecuencias tiene eso para nosotros? La primera cuestión, que es una cuestión estrictamente clínica, es que toda lengua es una lengua extranjera, empezando por la llamada, no casualmente, legua materna. Hay que entender esto para poder trabajar con el inconsciente. Y no solamente esto, sino que como lengua extranjera a nosotros mismos, estamos afectados de esa extranjeridad cuanto más familiar queremos hacerla.

Por eso el primer gesto que tiene Lacan es leerlo a Freud como si estuviera leyendo una lengua extranjera. Es complicado, porque pareciera que la lengua extranjera nos deja afuera. Cuando alguien habla otra lengua, esa lengua de alguna u otra manera nos excluye.

El inconsciente, que justamente está tejido por y en la lengua materna - la lengua que creemos saber y que hablamos cada uno de nosotros- se le presenta al sujeto como una lengua extranjera. Eso demuestra que cualquier lengua, incluso la que sabemos hablar, es una lengua extranjera para nosotros. Por definición, entonces, cada vez que hablamos no sabemos lo que decimos. Esto es lo que va tejiendo la posibilidad de plantear una escucha.

A partir de ahí, la unidad temática 1 plantea: "El sujeto de las psicosis: enunciación y deseo". Justamente porque partimos de esta definición de la lengua es que podemos sostener que, en las psicosis, el problema es cómo leer al sujeto. Y esto es importante como supuesto de lectura para el trabajo clínico con las psicosis. Seguramente a ese sujeto lo vamos a leer con una manera diferente de relacionarse a la alteridad que implica el Otro. Pero no porque 
haya una manera diferente de relacionarse al Otro tenemos que excluir de la lectura al sujeto.

El otro punto de la unidad temática número 1, tómenlo con un punto de suspensión o de interrogación: "No hay relación sexual, sino con Dios: Schreber teólogo”. Esto retoma el punto anterior.

Si la modalidad del Otro cambia en las psicosis, lo que Lacan plantea es que justamente esas versiones diferentes de la alteridad que podemos leer en el campo de las psicosis, nos dan también una diferente relación erótica a ese Otro, desde el mismo momento que la lengua está erotizada para el sujeto y veremos cómo para lo que planteamos como sujeto en las psicosis. Y esto arrastra una característica propia del lenguaje, y es, justamente, que el lenguaje nos hace gozar. En ese aspecto no hay una versión solamente lingüística del lenguaje, por más que en este momento del Seminario 3 pareciera que estamos frente al Lacan llamado estructuralista por algunos, que define el inconsciente como un lenguaje, vía la antropología y la lingüística estructuralista - ya que toma a Saussure, no sin Levy-Strauss, y realiza una inversión o una subversión del signo lingüístico, que es el elemento mínimo de la lengua - dando primacía al significante, presentando a la barra como resistente a la significación, e introduciendo, diferencialmente, toda la problemática de la significación.

A partir de esta operación que realiza Lacan, pareciera que ya estamos ante un terreno o un campo estrictamente lacaniano. Pero en el mismo momento en que Lacan intenta explicar esta primacía del lenguaje en la estructuración del sujeto, plantea que la relación del sujeto al lenguaje está erotizada (LACAN, I955-I956). Por lo tanto, hay una dimensión del len- guaje que no está destinada estrictamente a un campo de significación, sino que está destinada a un campo de erotización del sujeto. Y esto en la constitución misma del sujeto. Justamente, en este punto, si la relación al lenguaje es una relación erotizada, la clínica que se plantea no es una clínica que se sostenga, pura y exclusivamente, en el desciframiento de unas coordenadas simbólicas que el lenguaje pone en juego en la constitución del sujeto, porque ya la relación a la lengua está mediatizada por el fantasma, es decir, por una relación al Otro cuyo retorno nos obliga, de una $\mathrm{u}$ otra manera, a poner allí una imagen, un velo, algo que permita hacer de esa operación una relación, en algún punto, soportable.

Y ya que estamos en cuestiones eróticas con el Otro, el otro punto de esta unidad es el “Transexualismo”. Podríamos decir, el devenir mujer de Schreber, el devenir mujer en las psicosis, lo que se llama, comúnmente, el empuje a la mujer.

Preferimos plantearlo en términos de transexualismo. En ese punto Schreber nos convoca a leer un acontecimiento femenino en la economía de un delirante, que justamente goza a partir de una versión del Otro que lo hace gozar. Y en ese punto el transexualismo también recoge un problema marcadamente actual. Podríamos hacer la pregunta invertida: ¿el transexualismo es solamente un devenir posible, entre otros, de una estructura psicótica? La cura por travestismo, o el empuje a la mujer de un sujeto psicótico, nos plantea, como destino de las psicosis, la pregunta: ¿podemos plantear que todo transexualismo es una psicosis? Es un debate actual, porque está vinculado no solamente a toda la cuestión de la adquisición de derechos, sino a toda la problemática de género, es decir, que 
no sabemos muy bien qué es un hombre y qué es una mujer. Hoy alguien se declara hombre o se declara mujer y este acto le permite sostenerse como un ciudadano.

Lo que se plantea correlativamente a esto en términos de teoría, incluso en teoría de género, es una despatologización del campo de la diferencia sexual. Y la gran crítica que le hacen al psicoanálisis y a la clínica psicoanalítica es que patologiza todo. Entonces la cuestión del transexualismo estaría planteada en términos del devenir sintomático de una estructura. Ahora, ¿basta con despatologizar para ver cuál es el problema que está en juego?

El otro punto de la unidad es el problema del amor, y el punto se llama así: "El amor como psicosis y en las psicosis". Son dos cuestiones distintas. Por un lado, las locuras del amor, incluso del enamoramiento, lo que no implica hablar de psicosis y, por otro, cómo ama el psicótico, es decir, ¿qué versión del amor se pone en juego en las psicosis? Y esto es importante porque está en relación a la transferencia en las psicosis. Así, en la fórmula del delirio paranoico que escribió Freud, que a su vez le permitió formular la de los otros delirios, hay una declaración de amor: Yo (un hombre) lo amo (a otro hombre). Pero al mismo tiempo, uno podría decir, hay una declaración de odio, porque retorna persecutoriamente. Pero también se ha leído desde Schreber que esta fórmula es la que se rechaza porque tiene componentes homosexuales, entonces lo que retorna de eso tiene que ser rechazado o modificado. Lo importante aquí es que Freud, cuando explica este delirio paranoico, se sostiene en una fórmula que implica una declaración inconsciente de amor (FreUd, I9II).

Hay algo en la cuestión amorosa que en las psicosis nos plantea un problema a los analistas. Clásicamente se dice que el psicótico tiene un amor muerto, o amaría de tal manera que implicaría su muerte como sujeto. Lacan nos da una fórmula: el amor del psicótico es "un amor muerto" (LaCAn, I955-I956, p.363). Pero esto hay que tomarlo con pinzas, porque lo que hacemos con esto es presentar una casuística - presentar casos de enfermos- para demostrar esta fórmula de Lacan. Entonces demostramos que el amor muerto del psicótico se cumple, pero jamás presentamos un caso para interrogar esta fórmula. De este modo, el valor del ejemplo clínico se reduce a una confirmación de lo que ya se sabía de antemano. ¿Esto tiene que ver con la posición del analista o es una resistencia a la posición del analista? Vayan a leer el libro "El amor en las psicosis" de Miller y su grupo de trabajo (Miller, 2008).

Miller, para leer a Lacan, es un personaje rico y paradójico. En el seminario 3, como en todos, vemos al inicio que dice: "Texto establecido por Jacques-Alain Miller". Cabe preguntarnos qué nos ha quedado de Lacan, ya que tenemos tres cuestiones: por una lado, el Lacan seminarista, su enseñanza oral; después tenemos el registro que ha quedado de eso; y por último, el texto establecido de Miller, es decir, un texto escrito por otro. Por eso la pregunta clásica es qué queda de Lacan. Queda lo que nosotros tenemos que sostener: no tomar este texto como si fuera el único texto. Ahora, no es que vamos a llegar a lo que Lacan estrictamente dijo, porque esto es lo que hacen algunos grupos franceses cuando convocan a todos los que han sido asistentes de los seminarios para que con sus notas se llegue a establecer lo que dijo efectivamente Lacan. ¿Cómo hacemos para llegar a lo que Lacan dijo efectivamente? Y aquí nos preguntamos ¿Cómo 
hacemos para recoger en un escrito la enunciación, con todo lo que implica la enunciación de acto... fallido?

En este aspecto Miller hace una especie de limpieza del muerto y reduce a Lacan a un texto legible. La Academia está contenta. Entonces, tenemos un texto que supuestamente entendemos todos y después, cuando hacemos la lectura de ese texto que Miller hizo legible para nosotros, también nos encontramos con que no entendemos nada. Lacan sigue siendo una lengua extranjera para nosotros. Se dan cuenta que por más esfuerzos que hagamos para limpiar la enunciación, la enunciación se resiste a esta limpieza. Y esto es lo que nos interesa sostener, en relación a ustedes, con la lectura de Lacan. Por eso también la modalidad del parcial es oral individual. Es una modalidad enunciativa: tienen que dar cuenta por la vía de lo que dicen. Es importante que esta modalidad enunciativa nosotros la podamos sostener con la operación de la lectura. En ese punto es necesario hacer el ejercicio que Lacan nos plantea de entrada en el seminario 3, que es el de suspender cualquier gesto de comprensibilidad, es decir, suspender querer comprender. Es muy difícil, porque cuando suspendemos la comprensión, suspendemos al yo y todo lo que el yo arrastra, que no es ni más ni menos que el narcisismo. Por lo tanto, los invitamos al ejercicio anual de una herida narcisista, siempre abierta, y a la espera de alguna de sus cicatrices.

Voy a hacer una pequeña introducción al seminario 3 antes de meternos de lleno en él. Estamos el año 1955. Comúnmente se dice que Lacan ingresó al psicoanálisis por las psicosis, a diferencia de Freud que entró por la histeria. Es cierto, Lacan en- tra al psicoanálisis por las psicosis, o más precisamente por las locuras. El hecho que haya entrado por ahí, fundamentalmente a partir de la década del 30 , no lo confina a Lacan a ser un hijo de la psiquiatría. Entra por la locura, arma una tesis sobre la psicosis paranoica y sus relaciones con la personalidad. ${ }^{2}$ Entra entonces por la locura tratando de reformular la nosografía de la psiquiatría y tomando ciertos textos freudianos. Después tenemos el momento supuestamente "triunfal" de Lacan, el famoso estadio del espejo presentado en el año I 936 en el Congreso Psicoanalítico de Marieband, junto con un texto, dos años posterior, muy conocido de Lacan, y quizá aún muy poco leído, que son "Los complejos familiares" o "La Familia".

Tenemos, entonces, un Lacan, a fines de la década del 30 , que va de la psiquiatría a lo imaginario, es decir, al valor de la imagen en la estructuración del sujeto. Por lo tanto esto le permite, también, hacer una lectura de su tesis de psiquiatría.

Lacan comienza a cuestionar ciertas nociones psiquiátricas hasta tal punto, que resultado de eso es el texto "Acerca de la causalidad psíquica" de I946, ponencia oral de un Congreso de Psiquiatría, y que es un texto dirigido directamente a Henri Ey, organizador del mismo, quien venía planteando su teoría de la locura llamada órgano-dinamista, que consideraba que esta tenía una causa orgánica, por más que podía leérsela incorporando procesos dinámicos, incluso la metapsicología freudiana.

Para Ey, la locura tiene una causa orgánica. Por lo tanto, la causalidad psíquica que ayudaba a leer la locura a través de la captación de procesos dinámicos, se sostiene en una causalidad orgánica. Después podemos ver si esa causa orgánica era le- 
sional o era de una constitución congénita. No nos olvidemos que estamos entre el campo del acontecimiento y de lo que se trae, o sea la estructura, incluso para poder leer la cuestión de la causalidad.

Lo primero que vamos a encontrar en el seminario 3 es una declaración radical de Lacan y es lo que él llama, a esta altura de su discurso, "el gran secreto del psicoanálisis", y es que no hay psicogénesis (LACAN, I955-I956, p.I7). Sin embargo, en el año 46, Lacan decía otra cosa: se plantó en contra de la concepción organicista de Ey, incluso de su maestro Clérambault - ya que éste sostenía que la base de la causalidad, en términos de locura, era lo orgánico - y sostuvo de algún modo la psicogénesis en "Acerca de la causalidad psíquica.”

¿Cómo se estructura la psicogénesis en la locura según el Lacan de este momento? A partir del valor preponderante que tienen, en la constitución del sujeto, vía las identificaciones, las imágenes, o más específicamente la imago, planteando ya en estos dos textos -en El estadio del espejo del año 36 y en Acerca de la causalidad psíquica del 46- una causalidad psíquica que viene de los componentes imaginarios en la estructuración del sujeto. Por lo tanto, el valor de la imago, incluso de la imago paterna, en la estructuración del sujeto, es determinante de la causalidad psíquica y, en este punto, de la locura. Entonces, del 46 al 55, nueve años después, Lacan declara absolutamente lo contrario. ¿Por qué? Hay muchas razones. La primera es que cuatro años antes Lacan empieza a leer de otra manera a Freud, lo empieza a leer como si fuera una lengua extranjera, es decir, partiendo de lo que no sabe. En este ejercicio de lectura de Freud se constituye el famoso seminario de Lacan. Los primeros que dictaba en su casa estaban dirigidos a lo que los franceses llamaban los cinco casos freudianos. Aquí hay que resaltar una diferencia fundamental que es del orden del acontecimiento, mientras que los franceses contaban con una traducción malísima y fragmentaria de Freud, nosotros contamos ya desde antes de los años 30, cuando Freud aún vivía, con la bella y muy recomendable traducción de Ballesteros.

Lacan lo que hace es seguir la textura literal del texto freudiano: así lee a Freud en alemán. ¿Es posible enseñar una lengua que jamás hablé y de la que no tengo ni idea? Sí, es posible. No hay que intimidarse tanto, ni tenerle miedo a lo no familiar. A lo único que habría que temerle, decía Freud, es cuando lo no familiar retorna como familiar. Eso lo llama Freud lo siniestro, lo Unheimlich, es decir, cuando en lo no familiar me retorna algo familiar (Freud, I9I9). Pero a la extranjeridad, a lo no familiar, sería interesante que le tengamos paciencia.

Lacan, en el 32, cuando escribió su tesis doctoral, coqueteaba, por ejemplo, con el movimiento surrealista en Francia. El surrealismo fue una revolución en el campo del arte, y como tal, puntual y evanescente, sobre todo en la pintura y en la literatura, también en el cine. Lacan, entonces, se nos presenta como alguien que viene de la psiquiatría clásica y que forma parte, lateralmente, de este movimiento surrealista y, a la vez, va a los concurridos cursos de Kojève, que reunía a gran parte de la intelectualidad parisina en la década del 30, cursos sobre Hegel y sobre la fenomenología del espíritu de Hegel leído en clave heideggeriana. Y además de estas tres cuestiones, lee estrictamente a Freud. Bueno, todo este bagaje de Lacan es lo que se nos 
presenta en el Seminario 3: Lacan psiquiatra, surrealista, freudiano y hegeliano.

En la clase 5 del Seminario 1, "Los escritos técnicos de Freud", Lacan invita a Jean Hyppolite a que haga un comentario del texto "Die Verneinung" de Freud, del año I925. Por lo tanto Lacan convoca a un hegeliano a que lea un texto de Freud, en la lengua de Freud. El comentario que hace Hyppolite del texto de Freud es clave para entender este seminario (Hyppolite, I954). Por eso lean esta sesión 5 del Seminario I, el texto de Freud "La Negación", y la introducción y la respuesta que Lacan da a este comentario de Hyppolite que están en los escritos.

Entonces tenemos el texto de Freud leído por un especialista en Hegel en la propia lengua alemana. Hasta aquí lo que nosotros reconocemos de este texto de la negación es el famoso precepto clínico que allí donde está operando lo negado, podemos leer lo reprimido. Hyppolite tiene el maravilloso gesto de leer en la negación algo más allá de lo que les interesaba a los psicoanalistas de esa época. Entonces va a leer algo como filósofo, que es lo siguiente: ¿cómo se estructura el pensamiento en términos de juicio? Porque Freud hace una consideración de cómo se constituye el yo, y como el yo, constituyéndose, va armando una modalidad de estructuración que implica ciertas operaciones que están en el origen, que diferencia, en dicho texto, como juicios de existencia y juicios de atribución, justamente en la constitución de un yo placer, que se arma y se estructura a partir de la diferenciación entre lo placentero y lo displacentero - vivencia de satisfacción y vivencia de dolor -, ya desde la perspectiva freudiana del "Proyecto" de I 895 .
Hyppolite pone el acento ahí, hay algo que Freud nos muestra con respecto al origen. Esto es lo que le queda a Lacan para formular lo que retoma en el Seminario 3: que en el origen, justamente lo que encontramos es una determinación del sujeto por la vía de una economía que podemos plantearla en términos diferenciales, es decir, va a haber diferencias con respecto a aquello que constituye al sujeto, esto es lo que llama los tres registros. Lo simbólico, lo imaginario y lo real es el nombre de una conferencia de Lacan de I953, donde plantea que, en relación a la constitución del sujeto, hay que establecer un orden de diferenciación para poder leerla. Es decir, que el sujeto no se determina en un campo unificado, sino que se determina en un campo que está partido, que está diferenciado y que esos registros dan cuenta de la determinación del sujeto.

Dijimos, en el 46, Lacan pone el acento en la causalidad psíquica por la vía de la imagen operando en la identificación. Pero la imagen, o la imago ¿determina el sujeto o determina el yo? ¿Es lo mismo el yo que el sujeto? Justamente lo que le interesa al Lacan del 53 en adelante es no leer a Freud en clave yoica, es decir, no leerlo desde la segunda tópica y desde la función sintética del yo. Entonces en ese movimiento Lacan plantea que hay algo mucho más allá que el yo, y decide llamarlo sujeto - podría haberlo llamado Ello o Súper Yo -, pero decide plantearlo como sujeto, lo que no deja de sostener el arrastre que esa misma categoría plantea desde el discurso filosófico, por ejemplo.

El sujeto que plantea Lacan no queda reducido a la dimensión imaginaria del yo. Esto es justamente lo que constata en la práctica analítica, que se ha trans- 
formado en una clínica del yo. Entonces Lacan a partir de aquí plantea que la determinación del sujeto no viene solamente de lo imaginario, porque la imagen nos permite constituir una instancia que es el yo, pero no al sujeto. En el sujeto tenemos que plantear otra operación sobre esa, para poder decir que el sujeto no se reduce al yo. Es por eso que en sus dos primeros seminarios Lacan bascula entre estas dos dimensiones, prueba de ello es el esquema " $L$ " donde va a intentar leer la diferenciación de los registros en la causalidad psíquica. Por eso se dice que Lacan en este momento abandonaría el registro imaginario para trabajar en el simbólico, desde donde puede leer al sujeto. Esto implica que Lacan, en estos momentos, privilegie el orden simbólico en la constitución del sujeto, porque con el imaginario no podía dar cuenta de las relaciones del sujeto con el Otro, a la vez que empieza a introducir el problema de la realidad. Y ¿dónde se le empieza a plantear el problema de la realidad? En las psicosis, y no casualmente, porque Freud había leído a las psicosis en términos de realidad en "La pérdida de realidad en la neurosis y en la psicosis"(FreUd, 1924). De lo que se desprende que lo que me permitiría plantear una diferenciación del orden clínico y diagnóstico, sería el modo de plantear la relación a la realidad.

$¿ Y$ si la realidad no es tan real como suponemos? Para plantear este problema tengo que desmontar los presupuestos realistas de la realidad, es decir, tengo que plantear que ese modo de leer la problemática de las psicosis es insuficiente. El gran ejemplo es el de la alucinación. Si tomamos la alucinación visual, ¿es una percepción vacía de la realidad?
¿Invento una realidad nueva? ¿Habrá adecuación entre el sujeto que percibe y lo percibido? ¿Estamos todos tan seguros de que la realidad es el único lugar en el que podemos sostenernos? ¿Y si somos un sueño? ¿ $\mathrm{O}$ somos el sueño de otro?

Lacan empieza, entonces, a desmontar todos los prejuicios realistas. Por eso plantea otro registro, entre lo imaginario y lo simbólico, que es lo real. En este seminario todavía no hay una diferencia tan clara entre la realidad y lo real. Esto produce un equívoco que hace confundir lo real con la realidad y, a veces, con lo imaginario. En este equívoco tenemos que ver a dónde llega Lacan. Y en ese punto va a estar estrictamente lo que Lacan llama el decir psicótico, la labia del sujeto, cómo el psicótico dice, habla o testimonia. Partimos de que el inconsciente puede ser leído en términos de lenguaje, es decir, está primando ahí el registro simbólico. Si desde lo simbólico podemos establecer la diferencia entre el yo y el sujeto ¿Por qué no leemos a las psicosis en el mismo registro en el cual se nos presenta?: se nos presenta con lo que el psicótico dice.

El decir psicótico es un acontecimiento en el devenir de un psicótico. Ahora Lacan intenta desmontar los criterios de no adaptación a la realidad que supone las psicosis: el psicótico no está adaptado a la realidad porque alucina, ve cosas que no existen, porque delira. En vez de leerlo en términos de realidad fallida, Lacan lo lee en términos del decir, de palabra.

Teniendo en cuenta que es de nuestro interés el recorrido de la pregunta más que anteponerle a ésta una respuesta, vamos a hacer el ejercicio de acompañar a Lacan en la manera en la que él nos introduce en cierta práctica y en cierta dificultad de 
leer a Freud. Lacan hace un movimiento: comienza por un desvío, y ese desvío concierne de una u otra manera al problema planteado desde un lugar lateral. En el Seminario 3 la cuestión que va a situar lateralmente, pero que forma parte de la estructura misma que plantea -diferenciación entre neurosis y psicosis- es la cuestión de la Bejahung, que va a leer en un texto menor de Freud: "Die Verneinung”. Este texto Lacan lo venía introduciendo como problema, como señalamos anteriormente, desde el Seminario 1: "Los escritos técnicos de Freud", donde se planteaba el problema clásico de esa época, entre lo que se llamaba el problema del análisis del material o el análisis de las resistencias.

Lacan comienza a interrogarse por ciertas características de los analistas en función de alojar la palabra de los pacientes desde una concepción que desplazaba el problema inherente a la palabra por los problemas suscitados a nivel transferencial. Este desplazamiento -de la cuestión de la palabra a la cuestión transferencialintroducía el problema de la relación de objeto, en tanto era justamente el que se presentaba como obstáculo en la cuestión transferencial.

Lacan nos dice algo muy sencillo: si nosotros planteamos un sujeto que se relaciona con sus objetos y en el dispositivo analítico lo convocamos a hablar de esa dificultad, el problema no es la relación de objeto, sino cómo la relación de objeto está articulada a la palabra. No puedo separar rápidamente la cuestión del material a analizar -asociaciones, material simbólico- y el problema transferencial, porque lo que me permite poner en juego el problema del objeto es justamente la palabra, incluso donde las palabras faltan.
Lacan mueve el eje de la relación analítica: lo más importante no es el problema de la relación de objeto, sino el problema de cómo la relación de objeto está articulada en la palabra. Pero entonces, al desplazar el eje, en el desplazamiento mismo se arrastran los problemas inherentes a la palabra. Y la palabra, lo que arrastra es el problema del lenguaje. Por lo tanto, la introducción a la cuestión de las psicosis, está gobernada en Lacan por una tripartición del estatuto de la palabra: vector imaginario — problema de la significación-; registro simbólico —significante como elemento mínimo operando en el funcionamiento de la palabra, a partir de que el propio mensaje del sujeto le retorna desde el Otro en forma invertida-; lo real - ejercicio concreto de discurso. Aquí, el problema lingüístico es el de la diferencia entre plantearse cómo está compuesta una lengua -qué es una lengua, si es un caso particular del fenómeno del lenguaje- y cómo estaría compuesta para poder leerla, formalizarla y teorizarla.

Saussure es absolutamente magistral: teoriza aquello que puede teorizar. Teoriza el lenguaje en términos de casos particulares que serían las lenguas en sus diferencias, y a partir de ahí puede leer la lengua con un elemento, una unidad mínima, que es el signo linguiístico. Esto lleva a la definición saussureana de que la lengua es un sistema de signos, y como tal puede ser leída y formalizada (SAUSSURE, I9I6). El problema que de aquí se desprende es el problema del uso, porque una cosa es la lengua y otra es el uso de esa lengua.

Si Lacan diferencia los tres estatutos de la palabra, y del lado de lo real plantea el discurso concreto, que sería cómo el sujeto toma la palabra, tenemos como arrastre todo el problema que la lingüística plan- 
tea: la manera que cada quien tiene de hacerse cargo de ese acontecimiento que es el lenguaje.

En este punto Lacan va a leer el problema del origen. ¿Del origen de qué? Del origen de la simbolización, porque en ella Lacan supone que va a poder ser leído el sujeto en el dispositivo analítico. Entonces, para poder leer al sujeto, tengo que plantearme primero un operador de lectura, y segundo, para poder leer con ese operador, tengo que plantearme cómo está estructurado. Por lo tanto, comienza a preguntarse por el origen de lo simbólico.

Lacan sitúa un término en Freud para que nos hagamos cargo de los problemas que Freud nos plantea: por un lado la emergencia del sujeto, y, por otro, el operador que permita leer esa emergencia. El término que extrae Lacan del texto "Die Verneinung” de Freud, es, justamente, la Bejahung.

Esto hace que el Seminario 3 sea el primer intento sistemático de Lacan de formalizar, de una u otra manera, el registro simbólico en la determinación del sujeto, por eso va a leer en Freud el origen de la simbolización que supone dar cuenta de lo simbólico en la determinación del sujeto. Ese origen de la simbolización es lo que Lacan llama Bejahung: afirmación primordial. Por lo tanto, nos plantea dos caminos: hay Bejahung o no hay Bejahung. ¿Qué sucede si no hay Bejahung, si no existe esa afirmación primordial que sucede en el sujeto determinado por la vía del Otro? Hay algo que falla en el orden simbólico que nos permite plantear la diferencia entre neurosis y psicosis. Por lo tanto en la determinación simbólica del sujeto no puedo diferenciar neurosis y psicosis.

Lacan va a encontrar lo diferencial entre neurosis y psicosis en lo que él llama la Bejabung, en esta afirmación primera, e incluso primordial, del orden simbólico en la estructura del sujeto. Por eso en vez de enviarnos a leer Schreber de entrada, nos reenvía a releerlo a él y a como él ha leído a Freud y nos trae, un vez más, el famoso episodio de la alucinación del dedo cortado del hombre de los lobos. Allí Freud dice que habría una modalidad de retorno de lo reprimido que no es la misma modalidad en que esto retorna, por ejemplo, por la vía del síntoma. Allí hay algo distinto, una consecuencia que es una alucinación. Freud lo lee como un acontecimiento porque lo que retorna es diferente, no es un síntoma. Uno podría pensar que el hombre de los lobos frente al acontecimiento de la castración podría estar asediado de síntomas, pero no, lo que retorna es algo diferente, un episodio alucinatorio. Y lo que Lacan lee es que Freud lee allí, precisamente, una modalidad de retorno que no puede ser asimilada al retorno de lo reprimido. Por eso es que hay que volver a leer y a indagar el origen de la represión, para ver si encontramos allí algo de más, es decir, una modalidad de retorno que no se asemeje o que no se pueda homologar con el retorno de lo reprimido.

\section{II}

Vamos a situar lo que en el programa figura como destinos de la Bejahung. Que hablemos de los destinos de la Bejahung no implica que esté resuelto el problema de la Bejahung en sí mismo. Conservamos los términos en alemán en función de intentar leer una lengua extranjera en este par Bejahung —afirmación primordial-, Verwerfung —rechazo-, en las cuales Lacan sostiene la diferencia de mecanismos operando a nivel de las diferentes es- 
tructuras de neurosis y psicosis.

Recuerden que ya partíamos de un problema, Lacan lee a la Bejahung del texto de Freud "La negación" de I925: lo que se afirma -lo que se incluye-, y lo que se expulsa -lo que se rechaza-. A partir de una lectura que hace Lacan de Freud en su intento de ver, en cierto momento de su obra, cómo ciertos fenómenos de las psicosis aparecen en el campo de las neurosis, propone esta fórmula freudiana que lo rechazado en el interior, retorna desde lo exterior. Toma la alucinación del dedo cortado del Hombre de los lobos y plantea la posibilidad de leer una modalidad de retorno de lo rechazado que es diferente del retorno de lo reprimido. Por lo tanto, habría una modalidad de retorno que no podríamos asimilarla al retorno de lo reprimido, sobre todo por las consecuencias que tiene para el sujeto, es decir, una alucinación (LACAN, I955-I956).

A partir de ahí Lacan propone tomar el texto de Freud "La negación” y lo traduce junto a Hyppolite como "la denegación", por una razón básica: el término Verneinung en alemán contempla lo negado, es decir, el prefijo ver implica ya la negación en sí mismo. Fíjense que si yo hablo de Verneinung, Verwerfung, estoy hablando de un prefijo en la lengua alemana que es negativo, como Verdrängung. Propone traducirlo como denegación, porque justamente la denegación duplica lo negado $y$, en ese texto, Lacan va a leer el origen de la simbolización a partir de una operación primaria que es la Bejahung o afirmación primordial.

Uno podría suponer que partimos de un lugar, en ese lugar se produce un mecanismo que diferencia lugares, por ejemplo, un adentro y un afuera, y a partir de esa diferenciación tenemos consecuencias que pueden ser leídas diferencialmente. Es decir que partimos del hecho de que por una lado puede haber Bejahung o afirmación primordial y, por otro lado, hay un campo de negatividad de lo que se expulsa o se rechaza y a partir de ahí modalidades de retorno que pueden ser leídas a partir de esta diferencia. El problema de entrada es que la afirmación primordial que supone la Bejahung introduce un campo de negatividad que no es homogéneo al campo de partición binaria entre lo afirmado y lo negado. Por un lado tenemos la Verneinung, la negación, y por otro lado tenemos, por ejemplo, la Verwerfung. Se dan cuenta que tenemos una afirmación y más de una modalidad de negaciones. Por lo tanto, tenemos una operación que tiene como consecuencia abrir un campo que es heterogéneo a sí mismo. Lacan lee en la Bejahung un mecanismo que es solidario a la afirmación primordial, que es la expulsión, la expulsión de la que Freud hablaba, fuera del yo - ese yo placer originario que expulsa lo malo e incorpora, introyecta, lo bueno-, bajo el régimen del principio del placer. Por lo tanto esta operación sostiene primariamente un juicio de atribución, es decir, se atribuyen determinadas propiedades que delimitan lo que queda dentro del yo y lo que es expulsado, bajo la regulación del principio del placer: lo placentero adentro, lo displacentero afuera.

Este mecanismo de la afirmación primordial -fíjense que Bejabung implica el "ja” que significa sí, Bejahung es decir "sí" - esta Bejahung, que se constituye a partir de lo afirmado y, a la vez, de lo expulsado, incluye en su operación lo que Freud llama expulsión, lo que Lacan lee en la respuesta al comentario de Hyppolite sobre la negación de Freud, como Ausstossung. Sobre esto Lacan va a sacar el meca- 
nismo de la Verwerfung, del rechazo y, a la vez, sobre esto podemos leer en Freud el mecanismo de la Verneinung, o de la denegación, que es lo que acontece en el discurso cuando lo reprimido admite ser dicho en lo consciente bajo la modalidad de ser negado. Es decir, permite incluir lo reprimido en lo consciente, negándolo, a condición de que la represión se sostenga.

Freud es muy claro: admitir bajo la modalidad de lo negado algo en lo consciente no cancela la represión, no levanta la represión (FreUd, I925). Tópicamente la Verneinung acontece primero en el discurso y, a la vez, no es una negación radical, sino la negación que permite conservar lo negado, justamente bajo la modalidad de la negación misma. Por lo tanto, es conservación de lo negado. Pasa a lo consciente, "está dicho", pero a condición de que esté negado. Es una negación que es derivada secundariamente de la operación de la Bejahung, es muy distinta a la negatividad que se introduce por el campo de la expulsión radical que supone la primera operación de afirmación primordial.

Por lo tanto, tengo una afirmación, se podría decir, secundaria, y un campo de negatividad primario... Separo allí donde es difícil de separar... En este campo de negatividad primario que es solidario de la operación de afirmación primordial que es la Bejabung, tenemos, por un lado, lo que la Bejabung rechaza porque afirma - lo que expulsa- y, por otro lado, lo que Lacan lee, sobre esto, en términos de Verwerfung. Pregunta ¿la Verwerfung -lo que Lacan posteriormente va a proponer como forclusión- es asimilable a esta primera operación de expulsión en el seno de la Bejahung? ¿Es lo mismo lo que yo rechazo del Otro porque bajo el juicio de atribución no entra en la legalidad del principio del placer, que lo que está rechazado y retorna desde el exterior como no simbolizado?

Lacan va a ubicar que la Verwerfung, aquel mecanismo que nos permitiría diferenciar neurosis y psicosis, sería lo que se abre en el campo de afirmación primordial como otro camino, otro destino, diferente a los destinos que la Bejahung comporta en sí misma como operación: uno de ellos es la Verneinung o denegación. Pero la negación como denegación, es secundaria con respecto al campo que la afirmación primordial expulsa, que es la Ausstossung. Sobre esto Lacan lee el rechazo de un significante o de un elemento, o de algo del orden simbólico o de la simbolización.

Si yo tengo por un lado la afirmación de lo simbólico, en el mismo momento que afirmo algo, estoy negando: toda afirmación funda y encubre, al mismo tiempo, un campo de negatividad. Ese campo de negatividad lo podríamos leer, por un lado, desde la Verneinung - lo que se oculta, pero que se revela en el discurso, que es la negación secundaria- y por otro lado, desde lo que queda expulsado afuera, el campo de lo Ausstossung, de lo displacentero, de lo ajeno al yo.

Lacan insiste que lo que a él le interesa plantear con respecto a Freud es que si hay un campo de afirmación primordial de lo que viene del Otro, también tiene que haber un campo de negación primordial de lo que viene del Otro. Este campo de negación primordial de lo que viene del Otro, Lacan ¿lo asimila o no a lo que la Bejahung expulsa? Si y no, y vamos a ver dónde está la complicación acá.

Lacan va a situar los tres destinos de la Bejahung, de acuerdo a como los lee directa o indirectamente en Freud, en la clase 6 del Seminario 3: "El fenómeno psicótico y 
su mecanismo”. Allí, en la pag. I 8 dice:

La observación del presidente Schreber muestra en forma amplificada cosas microscópicas [Fíjense que a partir del delirio de Schreber Lacan va a situar "cosas microscópicas”, estamos como ven, al nivel del detalle]. Esto es justamente lo que me va a permitir aclarar lo que Freud formuló de la manera más clara a propósito de la psicosis, sin llegar hasta el final, porque en su época el problema no había alcanzado el grado de agudeza, de urgencia, que tiene en la nuestra en lo tocante a la práctica analítica [¿qué es lo que Lacan sitúa como "urgencia” que Freud no tenía?]. Dice, frase esencial que cité innumerables veces: algo que fue rechazado del interior reaparece en el exterior. A ella vuelvo. (LACAN, I955-I956, p.I I 8)

Es importante leer cómo Lacan insiste, pareciendo que siempre vuelve al mismo problema. Si nosotros reducimos este seminario a la forclusión del nombre del padre, perdemos de vista el recorrido de los problemas que Lacan plantea. Y el problema fundamental que a nosotros nos interesa plantear es que no es muy sencillo, clínicamente, separar neurosis de psicosis. De entrada, esta cuestión, es una cuestión dificultosa, hasta tal punto que Lacan se pregunta cuestiones básicas de las psicosis, como si hay psicosis infantil de la misma manera que hablamos de neurosis infantil. No es una pregunta tonta, porque nosotros con neurosis infantil captamos la posición de un sujeto por la vía del lugar que ha ocupado en relación al Otro que lo determina, fantasmáticamente hablando. Por lo tanto, escuchamos ahí algo de cierta historización encubierta, de ciertas marcas que determinan la posición fantasmática de un sujeto. ¿Podremos escuchar lo mismo a nivel de las psicosis? La pre- gunta es más radical: ¿hay una infancia en las psicosis? ¿hay un concepto psicoanalítico de infancia que pueda ser sostenido en el campo de las psicosis? Es necesario sostener esta pregunta de las psicosis en la infancia.

Les propongo articular el problema en los siguientes términos [dice Lacan]. Previa a toda simbolización —esta anterioridad es lógica, no cronológica- hay una etapa, lo demuestran las psicosis, donde puede suceder que parte de la simbolización no se lleve a cabo. Esta etapa primera precede toda dialéctica neurótica, fundada en que la neurosis es una palabra que se articula, en tanto lo reprimido y el retorno de lo reprimido son una sola y única cosa. Puede entonces suceder que algo primordial en lo tocante al ser del sujeto no entre en la simbolización, y sea, no reprimido, sino rechazado. (LACAN, I955-I956, p.II8)

O sea que lo rechazado, dice Lacan, supone una no simbolización: lo rechazado en función de una no-simbolización. Continúa: "Esto no está demostrado. Tampoco es una hipótesis. Es una articulación del problema” (LACAN, I955-I956, p.I I8). Fíjense la posición de lectura de Lacan: no está demostrado, pero tampoco es una suposición, una conjetura. Cuando dice articulación del problema, justamente es esto, recorrer el problema hasta ver adónde ese problema nos lleva.

La primera etapa [continúa Lacan] no es una etapa que tengan que ubicar en algún momento de la génesis. No niego, por supuesto, que lo que sucede a nivel de las primeras articulaciones simbólicas, la aparición esencial del sujeto, suscite preguntas, pero no se dejen fascinar por ese momento genético. El niñito al que ven jugando a la desaparición y retorno de un objeto, ejerci- 
tándose así en la aprehensión del símbolo, enmascara, si se dejan fascinar, el hecho de que el símbolo ya está ahí, enorme, englobándolo por todas partes, que el lenguaje existe, que llena las bibliotecas, las desborda, rodea todas vuestras acciones, las guía, las suscita, los compromete, puede en cualquier momento requerir que se desplacen y llevarlos a no importa dónde. Ante el niño que se está introduciendo en la dimensión simbólica olvidan todo eso. Coloquémonos, entonces, a nivel de la existencia del símbolo en cuanto tal, en tanto estamos sumergidos en él. (LACAN, I955-I956, p.I I 8-II9)

No a nivel de lo que el niño hace con el símbolo, sino que vamos a ubicarnos a nivel del símbolo. Está planteando algo del origen, pero no en sentido genético. Dice: "En la relación del sujeto con el símbolo, existe la posibilidad de una Verwerfung primitiva, a saber, que algo no sea simbolizado, que se manifestará en lo real" (LACAN, I955-I956, p.II9). No simbolización, Verwerfung, retorno de lo real.

Es esencial [continúa] introducir la categoría de lo real, es imposible descuidarla en los textos freudianos. Le doy ese nombre en tanto define un campo distinto al de lo simbólico. Sólo con esto es posible esclarecer el fenómeno psicótico y su evolución.

A nivel de esa Bejahung, pura, primitiva, que puede o no llevarse a cabo, se establece una primera dicotomía: aquello que haya estado sometido a la Bejahung, a la simbolización primitiva, sufrirá diversos destinos; lo afectado por la Verwerfung primitiva, sufrirá otro. (LACAN, I955-I956, p.II9)

Destinos de la Bejahung, diversos; destino de la Verwerfung, de lo rechazado, en singular, uno solo. Pero lo rechazado supone una no simbolización previamen- te para que retorne desde lo real como no simbolizado. Esa no simbolización, ¿es una no operatoria de la Bejahung?, es decir, lo no simbolizado, ¿implica que la $\mathrm{Be}$ jahung no aconteció? ¿O es un accidente en la Bejahung? Porque si yo digo lo no simbolizado, desconozco algo que Lacan sitúa de entrada, es muy cortito y lo pasamos de largo, Lacan dice: "Puede entonces suceder que algo primordial en lo tocante al ser del sujeto no entre en la simbolización.” (LACAN, I955-I956, p.I I8). Si dice "algo" es porque no está planteando todo lo simbólico, sino una parte de lo simbólico. Por lo tanto, si plantea una parte de lo simbólico hay algo de lo simbólico que está en juego. Eso que está en juego en lo simbólico ¿implica algo de la afirmación que está en juego en la Bejahung? Sigue Lacan y dice: "En el origen hay pues Bejahung, a saber, afirmación de lo que es, o Verwerfung" (Lacan, I955-I956, p.I20). Nuevamente sostiene la dicotomía. Continúa Lacan: "Entonces, en el seno de la Bejahung, ocurren toda clase de accidentes" (LACAN, I955-I956, p.I2I).

La Verwerfung ¿es un accidente de la Bejahung o no? Planteado como está planteado no: o hay Bejahung o hay Verwerfung. O una cosa o la otra. Sigue diciendo: "Nada indica que la primitiva sustracción haya sido realizada de manera adecuada" (LACAN, I955-I956, p.I2I).

Es decir, que un accidente de la $\mathrm{Be}$ jahung supone una inadecuada extracción de lo simbólico que viene del Otro por parte del sujeto, es decir, el texto que toma del Otro podría ser inadecuado para sostener a la Bejahung como tal. Sigue diciendo Lacan: "Por otra parte, lo más probable es que de aquí a mucho tiempo, seguiremos sin saber nada de sus motivos, precisamente porque se sitúa más allá de todo 
mecanismo de simbolización. Y si alguien sabe algo de ello algún día, es difícil que ese alguien sea el analista" (LACAN, I955I956, p.I2I). Mas adelante dice: "En su seno, entonces, se producirá todo lo que se puedan imaginar, en los tres registros de la Verdichtung, de la Verdrängung y de la Verneinung" (LACAN, I955-I956, p.I22).

Ubica entonces como los tres destinos de la Bejahung: $1^{\circ}$ ) a la Verdichtung; $2^{\circ}$ ) a la Verdrängung y $3^{\circ}$ ) a la Verneinung. Tres destinos de la Bejahung, donde ustedes podrán encontrar las tres unidades temáticas que continúan de la materia. De la Verdichtung, que se traduce normalmente como condensación, Lacan dice:

[...] es simplemente la ley del malentendido, gracias a la cual sobrevivimos, o hacemos varas cosas a la vez, o también gracias a lo cual podemos, por ejemplo, cuando somos un hombre, satisfacer completamente nuestras tendencias opuestas ocupando en una relación simbólica una posición femenina, a la par que seguimos siendo cabalmente un hombre, provisto de su virilidad, en el plano imaginario y en el plano real [pero en lo simbólico sigo siendo una mujer]. Esta función que, con mayor o menos intensidad es de feminidad, puede satisfacerse así en esa receptividad esencial que es uno de los papeles existentes fundamentales. No es metafórico: cuando recibimos la palabra de verdad recibimos algo. La participación en la relación de la palabra puede tener múltiples sentidos a la vez, y una de las significaciones involucradas puede ser justamente la de satisfacerse en la posición femenina, en cuanto tal esencial a nuestro ser. (LACAN, I955-I956, p.I22)

Es enorme lo que dice Lacan. Primero, que recibir la palabra del Otro nos hace a todos femeninos, es decir, si la palabra del
Otro es la que nos antecede, por definición, todos estamos de entrada en posición femenina, lo que él llama receptividad de la palabra, - creo que se cuida muy bien de no usar el término pasividad, que se asocia freudianamente a la posición femenina. Habla de la receptividad, porque en la receptividad hay algo activo de quien recibe. Este destino de la Bejahung es interesante porque ubica, por un lado, el recibir la palabra del Otro y, por otro lado, una potencia de lo simbólico enorme, porque lo simbólico me permitiría, bajo su legalidad, ser hombre o mujer. Justamente porque lo simbólico está articulado a cómo recibo la palabra del Otro. Por lo tanto la ley del malentendido que Lacan sitúa acá, es la ley del malentendido sexual: unidad tres del programa que se llama “Mujeres". ${ }^{3}$ En ese punto lo femenino opera de entrada en la determinación simbólica del sujeto y, a la vez, tal determinación, le permite estar en una posición y en otra a partir de la ley del malentendido sexual. No casualmente utiliza el término Verdichtung, es decir, condensación, lo que yo puedo juntar ahí donde previamente se plantean como separados.

En Lacan, después, la cuestión de la feminidad va a tener un horizonte mucho más rico que plantear la cuestión de lo masculino y lo femenino en términos de legalidad simbólica. Pero de entrada lo está planteando en estos términos, es decir, que ya desde el momento que recibo la palabra del Otro estoy en posición femenina. De ahí a plantear cuestiones más interesantes en relación a cuál sería la especificidad de lo femenino, incluso del goce femenino, hay un montón de cuestiones, pero hay que tener en claro que de entrada Lacan ubica como un destino de la Bejahung la ley del malentendido sexual. 
Por lo tanto, en esta ley no es sencillo diferenciar a un hombre de una mujer. En algún punto, ¿cómo podríamos decir lo que es un hombre o lo que es una mujer, si justamente hay una ley del malentendido sexual en juego? ¿Quién podría declararse hombre o mujer?

El segundo destino de la Bejabung es la Verdrängung, la represión, que Lacan nos dice:

[...] no es la ley del malentendido, es lo que sucede cuando algo no encaja a nivel de la cadena simbólica. Cada cadena simbólica a la que estamos ligados entraña una coherencia interna, que nos fuerza en un momento a devolver lo que recibimos a otro [la recepción implica una devolución]. Ahora bien, puede ocurrir que no nos sea posible devolver en todos los planos a la vez, y que, en otros términos, la ley nos sea intolerable.

No porque lo sea en sí misma, sino porque la posición en la que estamos implica un sacrificio que resulta imposible en el plano de las significaciones. Entonces, reprimimos: nuestros actos, nuestro discurso, nuestro comportamiento. Pero la cadena, de todos modos, sigue circulando por lo bajo, expresando sus exigencias, haciendo valer su crédito y lo hace por intermedio del síntoma neurótico. (LACAN, I955-I956, p.I22)

Por lo tanto, el síntoma es la exigencia de la cadena simbólica ahí donde justamente lo que no encaja intenta ser evitado. "Síntoma"4: título de la última unidad académica del programa, la cuarta. Dice Lacan:"En esto es que la represión es el mecanismo de las neurosis" (LACAN, I955-I956, p.I22).

Ubica claramente el síntoma planteado en términos de incidencia en la cadena simbólica. El síntoma sería una formación simbólica como destino de la afirmación primordial, de la Bejabung, como retorno de lo reprimido, justamente ahí donde el retorno nos permite leer lo reprimido. El síntoma, entonces, claramente está vinculado a un destino de la Bejahung en función de la cadena simbólica.

Y el último destino es la Verneinung, que es la que más hemos trabajado, la negación o la denegación. Dice Lacan:

La Verneinung es del orden del discurso, y concierne a lo que somos capaces de producir por vía articulada [la negación que Freud plantea, como negación secundaria, es la negación en el discurso]. El así llamado principio de realidad interviene estrictamente a este nivel. Freud lo expresa del modo más claro en tres o cuatro lugares de su obra, que recorrimos en distintos momentos de nuestro comentario. Se trata de la atribución, no del valor del símbolo, Bejahung, sino del valor de existencia. (LACAN, I955I956, p.I23)

Es decir, lo que primero está sometido al juicio de atribución entre lo placentero y lo displacentero, lo bueno y lo malo, después tiene que ser corroborado a nivel de lo que me represento en términos de realidad. Es decir, tengo el movimiento de que atribuyo propiedades que me permiten diferenciar un adentro y un afuera; en función de las propiedades que atribuyo establezco la existencia o no de aquello a lo cual le atribuyo las propiedades. Ese juicio de existencia, de acuerdo a como lo lee Lacan, va a estar ligado justamente al problema que más nos interesa, que es el problema del objeto. Se los leo textual porque nos acercamos al punto central:

A este nivel, que Freud sitúa en su vocabulario como el de juicio de existencia, le asigna, con una profundidad que se adelanta mil veces a lo que se decía en su época, la siguiente 
característica: siempre se trata de volver a encontrar un objeto. (LACAN, I955-I956, p.I23)

Aquí, en este punto, ya está planteada qué relación podría haber entre un destino de la afirmación primordial —la Bejahung - planteada en términos de negación articulada al discurso - Verneinung - y el problema del objeto. Continúa Lacan:

Toda aprehensión humana de la realidad está sometida a esta condición primordial: el sujeto está en busca del objeto de su deseo, más nada lo conduce a él. La realidad, en tanto el deseo la subtiende es, al comienzo alucinada. La teoría freudiana del nacimiento del mundo objetal, de la realidad, tal como es expresada al final de la Traumdeutung, [...] implica que el sujeto queda en suspenso en lo tocante a su objeto fundamental, al objeto de su satisfacción esencial (LACAN, I955-I956, p.I23).

Un objeto que hace que el sujeto quede en suspenso con respecto a la problemática del objeto. Yo le agrego a esto: Duelo, y digo y les propongo, siguiendo a Lacan en este movimiento, que el duelo es la primera y la más radical experiencia erótica que un sujeto tiene con un objeto. ${ }^{5}$

Veamos cómo lo plantea Lacan acá: la negación o denegación, por la vía de lo que implica un destino de la afirmación primordial de lo simbólico, nos lleva a la problemática del objeto perdido. Ese objeto perdido debería coincidir o no con una representación, pero ya la representación del objeto se da por vía alucinatoria. Por lo tanto, tengo una representación del objeto de la satisfacción que, en algún punto, no hace mas que plantearse alucinatoriamente. Por lo tanto, entre la alucinación y la realidad no hay mucha diferencia, y a la vez, entre lo que representa y lo representado hay un punto de imposibilidad que es el objeto. Porque no es lo mismo tener el objeto que tener la representación del objeto. Y no es lo mismo tener el objeto que tener la representación del objeto vía alucinatoria. Pero entonces la alucinación ¿Dónde queda? ¿y la realidad?

Esta experiencia de alucinación de un objeto en tanto el objeto se instituye, se restituye y se constituye como perdido, tiene un nombre y se llama Duelo. Por eso uno de los fenómenos más descriptos en el duelo son los fenómenos alucinatorios, a los cuales Freud estaba muy atento cuando escribe el texto "Duelo y Melancolía", a propósito de la "Amentia" de Meynert.

Ahora, la problemática del objeto en la vía de lo simbólico lo conduce a Lacan de lleno a la problemática del Seminario 10 de la angustia. En ese seminario plantea que la determinación del sujeto no está sostenida solamente por la cadena simbólica, sino por la incidencia de un resto de esa operación que es el objeto a como causa de deseo, objeto que es alojado en el fantasma, pero a la vez, no hay constitución del sujeto sin esa caída del objeto del campo del Otro, caída que implica, del lado del sujeto, su propio destino como objeto perdido.

En ese punto es importante captar que estos destinos nos permiten leer ciertos problemas, bastantes amplios, pero a la vez bien delimitados, de aquello que, según Lacan, seguimos llamando impropiamente la clínica psicoanalítica, y les presenta, en sus coordenadas fundamentales, la arquitectura argumentativa del programa y la propuesta general de nuestra cátedra. 


\section{Notas Ampliatorias}

1. La unidad a la que se hace referencia corresponde al programa de la materia "Ps. Clínica II A" de $6^{\circ}$ año de la carrera de Psicología de la Universidad Nacional de Rosario, vigente en el año 20r3. El texto que continúa se extrae de las transcripciones de clases teóricas de dicha materia fechadas los días 23 de abril de 2013 y 7 de Mayo de 20I3. Al finalizar el apartado I, en un intento de lograr mayor coherencia y en razón de la sucesión argumental expuesta, se han introducido interpolaciones correspondientes a la clase teórica dictada el 30 de abril de 2013 .

2. LaCAN, Jacques (1932) De la psicosis paranoica en su relación con la personalidad. Buenos Aires, Siglo XXI.

3. Unidad $\mathrm{N}^{\circ} 3$, correspondiente al programa antes citado.

4. Unidad $\mathrm{N}^{\circ} 4$, correspondiente al programa antes citado.

5. Unidad $\mathrm{N}^{\circ} 2$, correspondiente al programa antes citado.

\section{REFERENCIAS BIBLIOGRÁFICAS}

Balmés, F. (2002), Lo que Lacan dice del ser, Buenos Aires, Amorrortu Editores.

Czermak, M. (1987), Estudios psicoanalíticos de las psicosis. Pasiones del Objeto, Buenos Aires, Nueva Visión.

Freud, S. (I9II) "Puntulizaciones psicoanalíticas sobre un caso de paranoia (Dementia paranoides) descrito autobiográficamente", en Obras Completas (Vol. 12), Buenos Aires, Amorrortu. (I9I7) "Duelo y melancolía", en Obras Completas (Vol. 14), Buenos Aires, Amorrortu.

(I9I8) "De la historia de una neurosis infantil", en Obras Completas (Vol. 17), Buenos Aires, Amorrortu.

(I9I9) "Lo ominoso", en Obras Completas (Vol. 17), Buenos Aires, Amorrortu Editores.

(I924) "La pérdida de realidad en la neurosis y la psicosis", en Obras Completas (Vol. 19), Buenos Aires, Amorrortu Editores.

(1925) “La negación”, en Obras Completas (Vol. 19), Buenos Aires, Amorrortu Editores.

Hyppolite, J. (I954) "Comentario hablado sobre la Verneinung de Freud". En Lacan, J. Escritos, Buenos Aires, Siglo XXI,Volumen II, 837-846.

Kreszes, D. (I994), "Algunas consideraciones sobre la Verwerfung", en Redes de la letra, $\mathrm{N}^{\mathrm{O}} 3$, "Retorno del diálogo", Buenos Aires, Legere Editorial, 63-83.

LACAN, J. (I932) De la psicosis paranoica en su relación con la personalidad. Buenos Aires, Siglo XXI. 
(I938) "Los complejos familiares en la formación del individuo", Otros Escritos, Buenos Aires. Paidós, 33-96.

(I946) "Acerca de la causalidad psíquica”, Escritos, Buenos Aires, Siglo XXI, Volumen I, I 5 I-I90.

( I949) "El estadio del espejo como formador de la función del yo [je] tal como se nos revela en la experiencia psicoanalítica", Escritos, Buenos Aires, Siglo XXI, Volumen I, 99-I05.

(1953-I954) Seminario 1: Los escritos técnicos de Freud. Buenos Aires, Paidós.

(I954) "Introducción al comentario de Jean Hyppolite sobre la Verneinung de Freud", Escritos, Buenos Aires, Siglo XXI, Volumen I, 35I-36I.

( 1954 b) "Respuesta al comentario de Jean Hyppolite sobre la Verneinung de Freud", Escritos, Buenos Aires, Siglo XXI, Volumen I, 363-378.

(1955-I956) Seminario 3: Las Psicosis. Buenos Aires, Paidós.

$$
\text { (I957-I958) “De una cuestión }
$$

preliminar a todo tratamiento posible de la psicosis”, Escritos, Buenos Aires, Siglo XXI, Volumen II, 509-557.

(1962-1963) Seminario 10: La An-

gustia. Buenos Aires, Paidós.

Lanteri-Laura, G. (1994), "Proceso y psicogénesis en la obra de J. Lacan”, en Revista Litoral, N¹3, Córdoba, Ediciones Edelp, 25-43.

Maldonado, E. (2013), Lecturas de la negación, México, Editorial Me cayó el veinte.

Maleval, J. (2009). La forclusión del nombre del padre. El concepto y su clinica, Buenos Aires, Paidós.
Miller, J. (2008), El amor en la psicosis. Buenos Aires, Paidós.

Ortiz, A. (2009), La disolución freudiana de la psicosis, Buenos Aires, Editorial Sedimentos.

RABINovitch, S. (2000), Encerrados afuera. La preclusión, un concepto lacaniano, Barcelona, Ediciones del Serbal.

Saussure, F. (i9i6) Curso de lingüística general. Buenos Aires, Losada.

\section{RESEÑA CURRICULAR DEL AUTOR}

Damián CoIrini es psicoanalista, Psicólogo egresado de la Facultad de Psicología de la UNR. Docente e investigador de la UNR. Profesor Titular de la Cátedra de Clínica II de sexto año de la carrera de Psicología de la Facultad de Psicología de la UNR. 